\title{
Article \\ Evaluation of Clinical, Biochemical and Microbiological Markers Related to Dental Caries
}

\author{
Maria D Ferrer ${ }^{1}$ (D), Salvadora Pérez ${ }^{2}$, Aránzazu López Lopez ${ }^{1}$, José Luis Sanz ${ }^{2} \mathbb{D}$, Maria Melo $^{2, *}$, \\ Carmen Llena $^{2}$ (D) and Alejandro Mira ${ }^{1}$ (D)
}

1 FISABIO Foundation, Center for Advanced Research in Public Health, 46020 Valencia, Spain; ferrer_mde@gva.es (M.D.F.); arantxazo2014@gmail.com (A.L.L.); mira_ale@gva.es (A.M.)

2 Department of Stomatology, Universitat de Valencia, 46010 Valencia, Spain; doraperez11@hotmail.es (S.P.); jsanzalex96@gmail.com (J.L.S.); llena@uv.es (C.L.)

* Correspondence: m.pilar.melo@uv.es

Citation: Ferrer, M.D.; Pérez, S.; Lopez, A.L.; Sanz, J.L.; Melo, M.; Llena, C.; Mira, A. Evaluation of Clinical, Biochemical and Microbiological Markers Related to Dental Caries. Int. J. Environ. Res. Public Health 2021, 18, 6049. https://doi.org/10.3390/ ijerph18116049

Academic Editors: Yolanda Martinez Beneyto, Antonio J.

Ortiz Ruiz, Ascensión

Vicente Hernandez and Joerg Eberhard

Received: 4 May 2021

Accepted: 2 June 2021

Published: 4 June 2021

Publisher's Note: MDPI stays neutral with regard to jurisdictional claims in published maps and institutional affiliations.

Copyright: (C) 2021 by the authors Licensee MDPI, Basel, Switzerland. This article is an open access article distributed under the terms and conditions of the Creative Commons Attribution (CC BY) license (https:// creativecommons.org/licenses/by/ $4.0 /)$

\begin{abstract}
Our aim was to evaluate clinical, biochemical and microbiological markers related to dental caries in adults. A sample that consisted of 75 volunteers was utilized. The presence of caries and the presence of plaque and gingival indices were determined. Unstimulated salivary flow, $\mathrm{pH}$, lactate, Streptococcus mutans and Streptococcus dentisani were measured in the participants' plaque and saliva samples before and after rinsing with a sugar solution. Lactate in plaque was found to be significantly related to age, gender, tooth-brushing frequency, the presence of cavitated caries lesions and plaque and gingival indices $(p<0.05)$. The levels of $S$. dentisani in plaque increased significantly with tooth-brushing frequency $(p=0.03)$. Normalized plaque $S$. dentisani values and the percentage of $S$. dentisani were slightly higher in patients with basal lactic acid levels $\leq 50 \mathrm{mg} / \mathrm{L}$. After rinsing with a sugary solution, the percentage of $S$. mutans levels in plaque were higher in patients with lactic acid levels $>350 \mathrm{mg} / \mathrm{L}(p=0.03)$. Tooth-brushing frequency was the factor which was most associated with oral health. Women reflected better clinical and biochemical parameters than men. Low $\mathrm{pH}$ and high lactic acid levels tended to be associated with high caries rates. No association was found between bacteria levels and caries indices.
\end{abstract}

Keywords: caries; S. dentisani; S. mutans; lactic acid; $\mathrm{pH}$; dental plaque; saliva

\section{Introduction}

Dental caries is defined as a "biofilm-mediated, diet modulated, multifactorial, non-communicable, dynamic disease resulting in net mineral loss of dental hard tissues". It is determined by biological, behavioral, psychosocial and environmental factors. As a consequence of this process, a caries lesion develops [1]. The transition from health to disease occurs when there is a disturbance that modifies the conditions of the oral environment and favors the development of a more acid-producing and acid-tolerant microbial community [2]. This potential for tolerance and production of acids cannot be attributed to a single group of microorganisms, but to a bacterial consortium that interacts in a complex manner and that, under certain conditions, would increase in proportion or activity, to the detriment of other bacteria whose metabolic output would be less acidogenic [3]. When the environmental conditions change, the oral microbiota can also change and reverse the effect.

In the biofilm of a caries lesion, Streptococcus mutans is not the most numerous species; there are many other microorganisms with aciduric and acidogenic potential that are also present [4]. However, S. mutans has been extensively studied as it is an important producer of extracellular matrix and can rapidly modulate the formation of a cariogenic biofilm when aided by the presence of fermentable carbohydrates in the diet. Sucrose is considered the most cariogenic sugar because, in addition to being fermented by oral bacteria, it is an excellent substrate for the synthesis of extracellular (EPS) and intracellular 
(IPS) polysaccharides [5,6]. In contrast, the presence of microorganisms with arginolytic and ureolytic activity in the biofilm can buffer the $\mathrm{pH}$ and present a high cario-preventive potential and this is due to the production of ammonia as a final metabolite [7]. The presence of sucrose, a low buffering capacity of saliva, and a low $\mathrm{pH}$ have been shown to be important factors that hinder the production of alkali from arginine [8]. Thus, the final cariogenic potential of an oral biofilm is not only determined by the presence of sugarfermenting and acidogenic organisms but also by the levels of protective and $\mathrm{pH}$-buffering bacteria in the oral cavity. However, the simultaneous quantification of bacterial biomarkers of both types of organisms is rarely performed.

The microbial diversity of a caries lesion is considerably lower than that of dental biofilms [9]. Within the complex microbiota that has been identified in genomic studies, it has been observed that a large part of the microorganisms involved are commensal. Many have not yet been cultivated and have not even been assigned to scientific nomenclature yet $[10,11]$. It has been possible to identify a series of microbial species in the metagenomic studies of dental plaque, which are more compatible with dental health than others [12]. In 2014 a new species of Streptococci from the mitis group was described and named as Streptococcus dentisani [13]. When this bacterium was isolated in pure culture and grown in the presence of cariogenic organisms, such as S. mutans or Streptococcus sobrinus, it was observed that the bacterium inhibited or killed pathogens by means of bacteriocins [14]. It has also been demonstrated that $S$. dentisani has the capacity to metabolize arginine into ammonia, which neutralizes dental plaque $\mathrm{pH}$. Therefore, $S$. dentisani would provide a double anticariogenic mechanism; it would inhibit the growth of acidogenic bacteria, stimulate the formation of ammonium which results in a more favorable $\mathrm{pH}$ for dental health and it could act as a biomarker for beneficial oral bacteria [14].

Dental plaque constitutes the habitat in which microbial metabolic activity takes place and where both pathogenic and protective processes occur, which affects the development of the lesion. Urea, nitrate and arginine are the three main sources of alkali generation in plaque and saliva. Ammonia produced as a result of their metabolism can be an important endogenous inhibitory factor of the acidogenic microbiota and caries development by neutralizing acids and stabilizing the oral microbiota [15-19]. Thus, the levels of ammonia, $\mathrm{pH}$ and organic acids, such as lactate, could act as biomarkers to indicate the acidogenicity of oral communities and may be related to the risk of developing caries lesions. However, it is unclear whether the levels of these compounds have a better diagnostic and predictive value when measured in dental plaque or in saliva.

As early as 1940, Stephan reported that between $2 \mathrm{~min}$ and $15 \mathrm{~min}$ after rinsing with a sugary solution, the $\mathrm{pH}$ of dental plaque drops, lactic acid being mainly responsible for this drop, and then returns to its basal level around the 40 min mark [20]. This is possible thanks to the implementation of buffer mechanisms among which bicarbonate, urea and arginine stand out $[18,21-23]$. Thus, not only is the basal $\mathrm{pH}$ important as a measure of acidogenicity but also the level achieved after fermentation takes place. Accordingly, in the current manuscript $\mathrm{pH}$ and lactate levels before and after the $\mathrm{pH}$ drop caused by sugar exposure were measured.

The responsiveness of saliva and dental plaque when subjected to acid stress will be an indicator of the ability to compensate and balance acids in the oral environment either through the salivary compensatory mechanisms or the already described mechanisms of action of microorganisms such as S. dentisani [14]. To the authors' knowledge, there are currently no studies that evaluate the possible association between the response to acid stress in saliva and plaque with the levels of S. mutans and S. dentisani, simultaneously, and its association with previous clinical records of caries and biochemical salivary and plaque parameters. Therefore, the present study aims to simultaneously analyze clinical, biochemical and microbiological factors potentially related to caries experience in a sample of adults. The following elements were assessed: plaque and gingival indices; salivary flow; salivary and plaque $\mathrm{pH}$; and salivary and plaque lactate before and after sugar exposure. Additionally, the presence of $S$. mutans and the presence of $S$. dentisani in both plaque and 
saliva were quantified by quantitative PCR. Finally, the associations of all these parameters with dental caries experience, gender and tooth-brushing frequency were evaluated in order to better understand their relationships relative to one another and to identify potential biomarkers and risk predictors of the disease.

\section{Materials and Methods}

This study is part of two CECT 7746 clinical trials carried out in collaboration between the FISABIO Foundation and the Lluís Alcanyis Foundation of the Universitat de València. It was approved by the DGSP-CSISP Ethics Committee with project codes ABB-SdentColonization and ABB-dentisani 2015. The study began in 2016 and was completed in 2018. Compliance of the protocol and surveillance of the study was performed by the external CRO Effice (Madrid, Spain).

\subsection{Participant Selection Process}

In order to carry out the present study, 184 volunteers were recruited. Informed consent was obtained from all subjects involved in the study. Inclusion criteria for the selection of participants were: age between 18 and 65 years; basal salivary pH (after brushing with water) $\leq 7$; at least 21 teeth present in the oral cavity; previous caries experience and/or presence of active caries lesions; and the absence of other oral diseases. Patients with chronic diseases; use of medication or previous procedures, such as head and neck radiotherapy or pathologies that reduce salivary flow; basal $\mathrm{pH}$ at the time of recruitment $>7$; and/or absence of previous caries experience; and/or active caries lesions were excluded. Individuals taking antibiotics during the previous 3 months or regular use of oral antiseptic mouthwashes during the previous week were also excluded. After applying the inclusion and exclusion criteria, a total of 75 participants were selected.

\subsection{Clinical Examination and Sample Collection}

After being included in the study, each participant received an appointment to which he/she had to attend without having brushed his/her teeth since the night before. In this appointment, which was carried out between 4:00 p.m. and 7:00 p.m., frequency of daily tooth-brushing was recoded. A sample of unstimulated basal saliva obtained by drooling was taken for five minutes to determine salivary flow by considering values from 0.25 to $0.3 \mathrm{~mL} / \mathrm{min}$ as the normal secretion rates (sample 0 ). From these salivary samples, the buffer $\mathrm{pH}$ was determined.

Subsequently, an oral examination was performed and the plaque and gingival index of Silness and Löe and Löe and Silness [24], respectively, were determined. Additionally, the supragingival biofilm of all teeth surfaces was collected in two $1.5 \mathrm{~mL}$ Eppendorf tubes using a sterile dental excavator. Biofilm from quadrants 1 and 3 were deposited in $100 \mu \mathrm{L}$ phosphate buffer solution (PBS) for its conservation until the subsequent extraction of bacterial DNA. Biofilm from quadrants 2 and 4 were deposited in $100 \mu \mathrm{L}$ sterile $\mathrm{H}_{2} \mathrm{O}(\mathrm{pH}=7)$ for the subsequent determination of $\mathrm{pH}$ and lactic acid content after sugar exposure.

After the plaque sample collection, patients were instructed to brush their teeth $2 \mathrm{~min}$ with water using a manual toothbrush. The presence of caries was then assessed using the ICDAS II criteria by the same experienced explorer in all participants [25].

Next, an additional sample of unstimulated saliva obtained by drooling (sample 1) was collected, in which the $\mathrm{pH}$ was determined. The participants then rinsed with a 10\% sugar solution for $1 \mathrm{~min}$ and $10 \mathrm{~min}$ after rinsing a final salivary sample was collected (sample 2).

\subsection{Determination of Salivary $p H$}

Salivary $\mathrm{pH}$ was determined from samples 0,1 and 2 by means of a reflectometer (Reflectoquant; Merck, Darmstadt, Germany) which was calibrated with the corresponding pH strips (reference: 116996). 


\subsection{Determination of Biofilm $\mathrm{pH}$ and Lactate Content}

For the determination of biofilm lactate content, $30 \mu \mathrm{L}$ of the initial sample $(100 \mu \mathrm{L}$ $\mathrm{H}_{2} \mathrm{O}+$ biofilm) was deposited onto the test strips. After $7 \mathrm{~min}$, they were introduced into the reflectometer for their measurement ( $\mathrm{t} 0$ ) after calibration with the lactic acid strips (reference: 116127). For the measurement of biofilm pH, $30 \mu \mathrm{L}$ of the same sample was deposited onto the corresponding test strips and, after $10 \mathrm{~s}$, they were introduced into the reflectometer. Then, $40 \mu \mathrm{L}$ of $20 \%$ sucrose solution was added to the initial sample, thus obtaining a final sucrose concentration of $10 \%$. Immediately afterwards, the samples were introduced in a laboratory oven at $37^{\circ} \mathrm{C}$ for a $10 \mathrm{~min}$ incubation period. After the incubation period, the $\mathrm{pH}$ and lactic acid (t10) were measured again.

\subsection{Count of S. mutans, S. dentisani, and Total Bacterial Count}

The microorganism count was performed in plaque and saliva samples: $250 \mu \mathrm{L}$ of basal saliva (sample 0 ) and the plaque samples from quadrants $1 / 3$ resuspended in $100 \mu \mathrm{L}$ of PBS buffer were used. First, the DNA was extracted in an automated process, using the MagnaPure LC JE379 equipment and the MagnaPure LC DNA Isolation Kit that are both from Roche (Basel, Switzerland), after an enzymatic lysis [26]. A fluorometric method (Quant-iT PicoGreen dsDNA Assay, Invitrogen) was used to quantify the extracted DNA. The reactions for the quantification of S. mutans, S. dentisani and total bacteria were carried out by means of qPCR (quantitative Polymerase Chain Reaction) with the LightCycler 480 equipment and the LightCycler 480 SYBR Green I Master Mix kit (Roche, Basel, Switzerland).

The specific primers used for the quantification of S. dentisani (CkSdF and CkSdR) [14] amplify a 77 base pair region of the carbamate kinase gene. For the quantification of S. mutans, primers which were already reported in the literature were used which amplify a 415 base pair fragment of the glycosyl transferase gene [27]. In the case of total bacteria, the target gene was the 16S rDNA ribosomal gene that is highly conserved in the Bacteria Domain. The primers used (515F-789R) amplify a region of 274 base pairs [28,29].

All amplification reactions were carried out in a final volume of $20 \mu \mathrm{L}$ containing $1 \mu \mathrm{L}$ of template DNA (5-22 ng/ $\mu \mathrm{L}), 10 \mu \mathrm{L}$ of LightCycler 480 SYBR Green I Master Mix, $0.4 \mu \mathrm{L}$ of each primer and $7.2 \mu \mathrm{L}$ of nuclease-free water. The thermocycling program used is described as follows: an initial denaturation step at $95^{\circ} \mathrm{C}$ for $5 \mathrm{~min}, 40$ cycles of $10 \mathrm{~s}$ at $95^{\circ} \mathrm{C}, 20 \mathrm{~s}$ at $65^{\circ} \mathrm{C}$ (for total bacteria it was reduced to $58^{\circ} \mathrm{C}$ ) and $25 \mathrm{~s}$ at $72{ }^{\circ} \mathrm{C}$. All reactions were performed in duplicates as well as their corresponding positive and negative controls.

\subsection{Statistical Analysis}

The ICDAS II values were recalculated as Decayed, Missing and Filled Teeth (DMFT) values. In component D, cavitated caries (caries ICDAS codes 3-6 and restauration ICDAS codes 7 and 8 ) on the one hand and cavitated and not cavitated caries on the other (caries ICDAS codes 1-6 and restauration ICDAS codes 7 and 8 ) were recoded. In components M and F, ICDAS code 97 and restoration ICDAS codes 3-6, respectively, were included [30].

Using the Kolmogorov-Smirnov test, it was determined if the quantitative variables did not follow a normal distribution. Non-parametric tests were used if this was the case. The Kruskal-Wallis test was used to compare tooth-brushing frequency and quantitative variables. The Mann-Whitney U test was used to compare gender with the quantitative variables. Chi-squared test was used for comparison between gender and tooth-brushing frequency. Box plot graphs representing median and Inter quartile range (IQR) were used for presenting data. Finally, correlation analyses were performed between the different study parameters using the Spearman correlation coefficient. In all cases, a significance level of $95 \%$ was used.

\section{Results}

The sample consisted of 24 men (32\%) and 51 women (68\%) with a mean age of $34.72 \pm 10.84$ years. 


\subsection{Analysis of Clinical, Biochemical and Microbiological Variables by Gender}

Analyses by gender revealed that caries indices and their components were higher for men than for women, except for the filled teeth that were slightly higher for women. After analyzing their components, missing teeth values for men were significantly higher than for women $(p=0.01)$. Plaque index was significantly higher in men than in women $(p=0.01)$. Men brushed their teeth significantly less frequently than women $(p=0.02$, Chi-squared test) (Figure 1A). The $\mathrm{pH}$ of saliva or of plaque at different time points were similar in men and in women (Figure 1B). Plaque lactate levels at both $\mathrm{t} 0$ and $\mathrm{t} 10$ were significantly higher for men (Mann-Whitney U test) $(p<0.01)$ (Figure 1C). The levels of S. mutans and S. dentisani were obtained in saliva normalizing by volume (CFUs $/ \mathrm{mL}$ ) and in plaque after normalizing by the total bacterial DNA present (CFUs/ng). Values for S. mutans were significantly higher in men than in women $(p<0.01)$. Figure 1D shows median and IQR for the levels of $S$. mutans and $S$. dentisani transformed in $\log 10$ values.

(A). Caries, plaque and gingival indices and salivary flow.

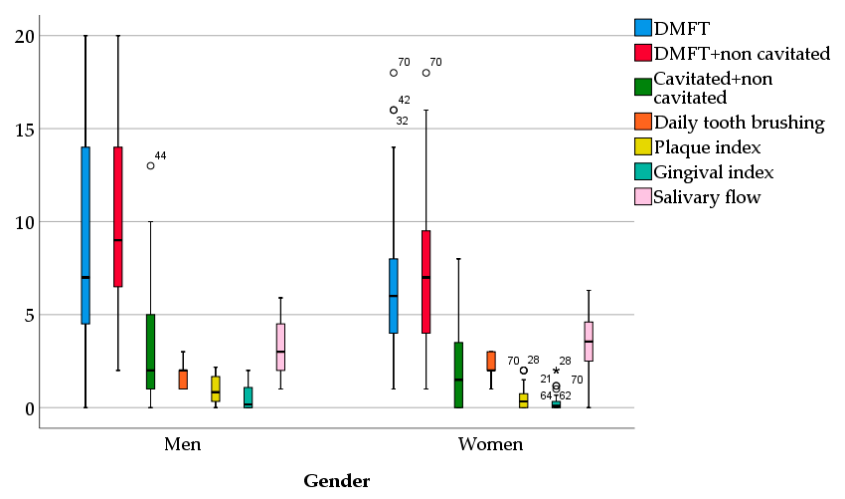

(C). Lactate $(\mathrm{mg} / \mathrm{L})$.

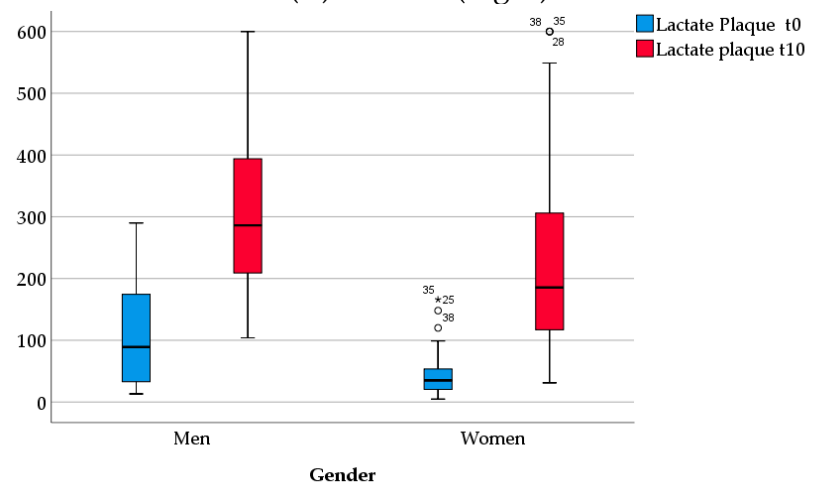

(B). $\mathrm{pH}$ in saliva and plaque.

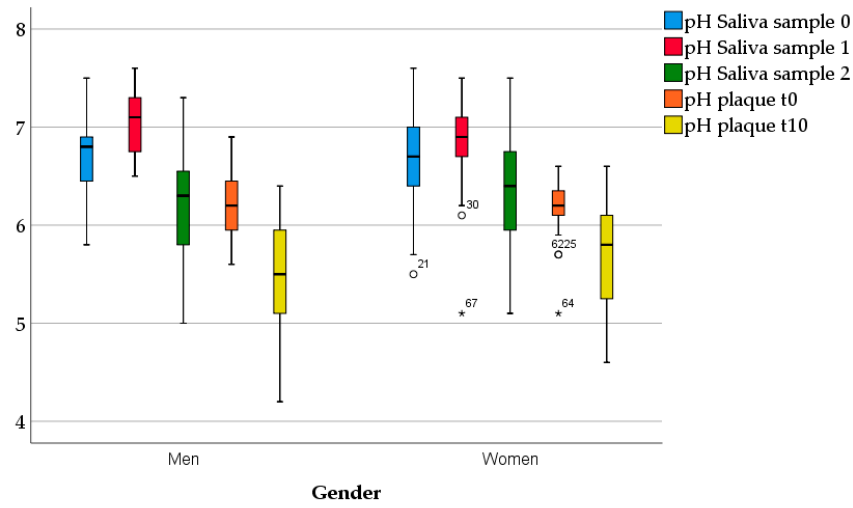

(D). S. mutans and S. dentisani levels in saliva and plaque.

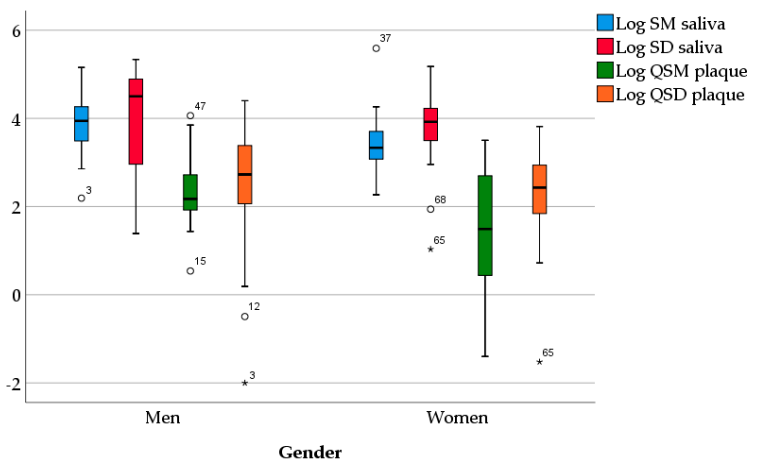

Figure 1. Clinical, biochemical and microbiological variables by gender. The graphs show medians and IQR values for the different variables. (A) DMFT = ICDAS codes 3-6 + restoration ICDAS codes 7 and $8+$ missing teeth due to caries + filled teeth due to caries. DMFT with non-cavitated lesions = DMFT + ICDAS codes 1-6 + restoration ICDAS codes 7 and 8. (B) $\mathrm{pH} \_$saliva $($sample 0$)=$ basal salivary $\mathrm{pH}$. pH_saliva (sample 1) = salivary $\mathrm{pH}$ after tooth-brushing. pH_saliva (sample 2) = salivary $\mathrm{pH}$ after sugar rinse. $\mathrm{pH}$ plaque $\mathrm{t} 0=$ plaque $\mathrm{pH}$ before sugar rinse. $\mathrm{pH}$ plaque $\mathrm{t} 10=$ plaque $\mathrm{pH}$ after sugar rinse. $(C)$ Lactate plaque $\mathrm{t} 0=$ plaque lactate levels before sugar rinse $(\mathrm{mg} / \mathrm{L})$. Lactate plaque $\mathrm{t} 10=$ plaque lactate levels after sugar rinse (mg/L). (D) Log SM saliva = Log10 transformation of normalized CFUs/mL of S. mutans in saliva, Log SD saliva $=\log 10$ transformation of normalized CFUs $/ \mathrm{mL}$ of $S$. dentisani in saliva. Log QSM plaque $=\log 10$ transformation of normalized CFUs/ng of $S$. mutans in plaque, Log QSD plaque = Log10 transformation of normalized CFUs/ng of $S$. dentisani in plaque. The expected loss in statistical power due to the difference in male:female ratio is $<0.05$.

\subsection{Analysis of Clinical, Biochemical and Microbiological Variables by Tooth-Brushing Frequency}

Participants who brushed their teeth two or three times a day presented lower values of DMFT (with or without non cavitated lesions) than those that brushed only once a day. 
Components $\mathrm{D}$ and $\mathrm{M}$ were also lower in these patients $(p<0.05)$. Plaque and gingival indices were significantly lower in participants who brushed their teeth three times a day compared to those that brushed once per day $(p<0.05)$ (Figure 2A). Lactate values at t10 decreased significantly when the tooth-brushing frequency increased $(p<0.05)$ (Figure $2 \mathrm{C}$ ). The $\mathrm{pH}$ values and normalized levels of $S$. mutans and $S$. dentisani in saliva (CFUs $/ \mathrm{mL}$ ) or in plaque (CFUs/ng) did not vary significantly with tooth-brushing frequency (Figure 2B,D).

(A). Caries, plaque and gingival indices and salivary flow.

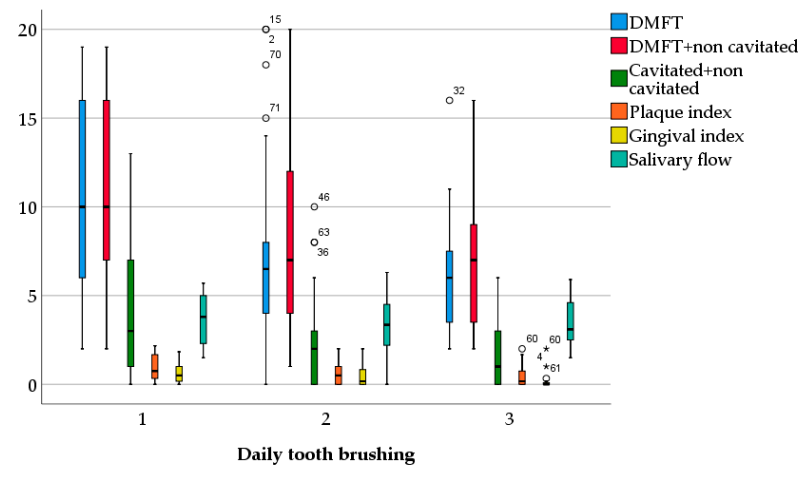

(C). Lactate levels (mg/L).

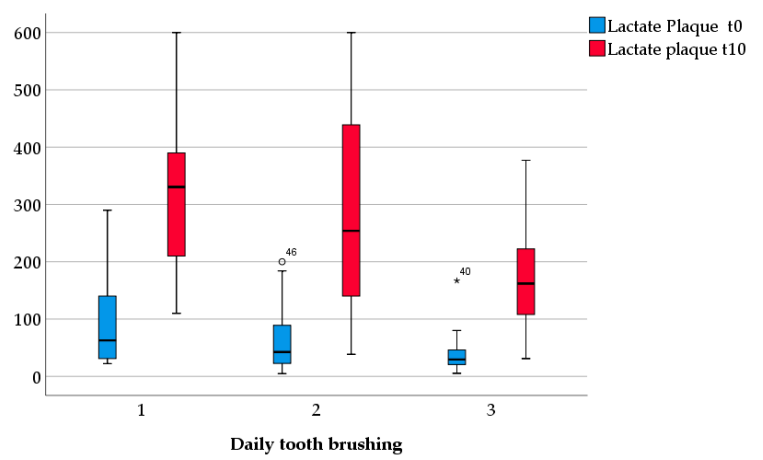

(B). $\mathrm{pH}$ values in saliva and plaque.

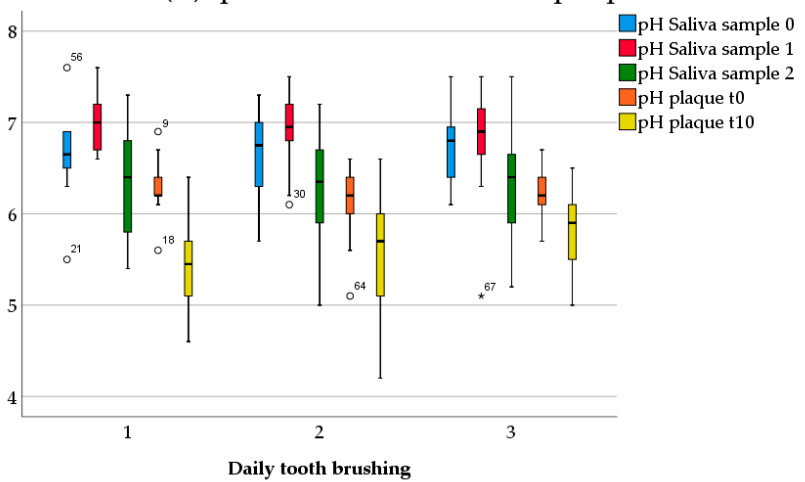

(D). S. mutans and S.dentisani in saliva and plaque.

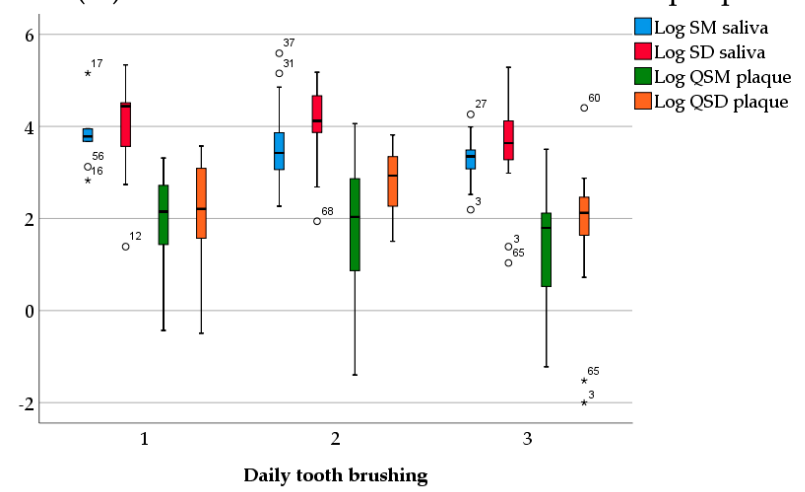

Figure 2. Clinical, biochemical and microbiological variables by daily tooth-brushing. Graphs show medians and IQR values for the different variables. (A) DMFT $=$ ICDAS codes 3-6 + restoration ICDAS codes 7 and $8+$ missing teeth due to caries + filled teeth due to caries. DMFT with non-cavitated lesions = DMFT + ICDAS codes 1-6 + restoration ICDAS codes 7 and 8. (B) pH_saliva (sample 0$)=$ basal salivary pH. pH_saliva (sample 1) = salivary pH after tooth-brushing. $\mathrm{pH} \_$saliva (sample 2 ) = salivary $\mathrm{pH}$ after sugar rinse. $\mathrm{pH}$ plaque $\mathrm{t} 0=$ plaque $\mathrm{pH}$ before sugar rinse. $\mathrm{pH}$ plaque $\mathrm{t} 10=\mathrm{plaque}$ $\mathrm{pH}$ after sugar rinse. $(\mathrm{C})$ Lactate plaque $\mathrm{t} 0=$ plaque lactate levels before sugar rinse $(\mathrm{mg} / \mathrm{L})$. Lactate plaque t10 = plaque lactate levels after sugar rinse (mg/L). (D) Log SM saliva = Log10 transformation of normalized CFUs $/ \mathrm{mL}$ of $S$. mutans in saliva, Log SD saliva= Log10 transformation of normalized CFUs $/ \mathrm{mL}$ of S. dentisani in saliva. Log QSM plaque $=$ Log10 transformation of normalized CFUs/ng of S. mutans in plaque, Log QSD plaque $=$ Log10 transformation of normalized $\mathrm{CFUs} / \mathrm{ng}$ of $S$. dentisani in plaque.

\subsection{Analysis of Clinical and Biochemical Variables}

Table 1 shows the correlation analysis of the different clinical and biochemical variables analyzed (Spearman's correlation coefficient). A positive significant correlation was found between plaque index and gingival index and plaque $\mathrm{pH}$ and lactate levels at $\mathrm{t} 0$ and $\mathrm{t} 10$ $(p<0.05)$. The basal saliva $\mathrm{pH}$ (sample 0$)$ was significantly positive correlated with saliva $\mathrm{pH}$ after brushing (sample 1) and after sugar rinse (sample 2$)$, respectively $(p<0.05)$. Plaque $\mathrm{pH}$ and lactate levels at $\mathrm{t} 0$ and $\mathrm{t} 10$ were also significantly positive correlated $(p<0.05)$. 
Table 1. Analysis of the correlations (Correlation Coefficients (CC) and $p$-values) between the quantitative variables assessed. Significant correlations are bolded.

\begin{tabular}{|c|c|c|c|c|c|c|c|c|c|c|c|c|c|c|c|c|c|}
\hline & & Age & D_Cavitated 1 & $\begin{array}{c}\text { D_non } \\
\text { Cavitated }{ }^{2}\end{array}$ & $\mathrm{M}^{3}$ & $\mathrm{~F}^{4}$ & $\operatorname{DMFT}^{5}$ & $\begin{array}{c}\text { DMFT + Non } \\
\text { Cavitated }{ }^{6}\end{array}$ & $\mathrm{PI}^{7}$ & $\mathrm{GI}^{8}$ & $\begin{array}{c}\text { Salivary } \\
\text { Flow }\end{array}$ & $\begin{array}{c}\mathrm{pH} \text { _Saliva } \\
(\text { Sample 0) }\end{array}$ & $\begin{array}{c}\mathrm{pH}_{\text {_Saliva }} \\
\text { (Sample 1) }{ }^{10}\end{array}$ & $\begin{array}{c}\mathrm{pH} \_ \text {Saliva } \\
\text { (Sample 2) } \\
11\end{array}$ & PH_Plaque_t0 12 & pH_Plaque_t10 13 & $\begin{array}{c}\text { Lactate } \\
\text { Plaque_to } 14\end{array}$ \\
\hline D_cavitated & $\begin{array}{l}\mathrm{CC} \\
\mathrm{p}\end{array}$ & $\begin{array}{l}0.11 \\
0.34 \\
\end{array}$ & & & & & & & & & & & & & & & \\
\hline D_non cavitated & $\begin{array}{l}\mathrm{CC} \\
\mathrm{p} \\
\end{array}$ & $\begin{array}{l}-0.17 \\
0.13 \\
\end{array}$ & $\begin{array}{c}-0.20 \\
0.07 \\
\end{array}$ & & & & & & & & & & & & & & \\
\hline M & $\begin{array}{l}\mathrm{CC} \\
\mathrm{p}\end{array}$ & $\begin{array}{l}0.60 \\
0.00\end{array}$ & $\begin{array}{l}0.08 \\
0.48\end{array}$ & $\begin{array}{c}-0.02 \\
0.80\end{array}$ & & & & & & & & & & & & & \\
\hline $\mathrm{F}$ & $\begin{array}{l}\mathrm{CC} \\
\mathrm{p} \\
\end{array}$ & $\begin{array}{l}0.17 \\
0.14 \\
\end{array}$ & $\begin{array}{l}-0.32 \\
0.00 \\
\end{array}$ & $\begin{array}{l}-0.14 \\
0.23 \\
\end{array}$ & $\begin{array}{l}0.20 \\
0.08\end{array}$ & & & & & & & & & & & & \\
\hline DMFT & $\begin{array}{l}\mathrm{CC} \\
\mathrm{p}\end{array}$ & $\begin{array}{l}0.33 \\
0.00\end{array}$ & $\begin{array}{l}0.262 \\
0.02 \\
\end{array}$ & $\begin{array}{c}-0.23 \\
0.04 \\
\end{array}$ & $\begin{array}{l}0.50 \\
0.00\end{array}$ & $\begin{array}{l}0.69 \\
0.00 \\
\end{array}$ & & & & & & & & & & & \\
\hline D cavitated + non cavitated & $\begin{array}{l}\mathrm{CC} \\
\mathrm{p}\end{array}$ & $\begin{array}{l}-0.03 \\
0.79\end{array}$ & $\begin{array}{l}0.72 \\
0.00\end{array}$ & $\begin{array}{l}0.42 \\
0.00\end{array}$ & $\begin{array}{l}0.06 \\
0.59\end{array}$ & $\begin{array}{c}-0.32 \\
0.00\end{array}$ & $\begin{array}{l}0.15 \\
0.17\end{array}$ & $\begin{array}{l}0.36 \\
0.00\end{array}$ & & & & & & & & & \\
\hline PI & $\begin{array}{l}\mathrm{CC} \\
\mathrm{p}\end{array}$ & $\begin{array}{l}0.21 \\
0.06 \\
\end{array}$ & $\begin{array}{l}0.39 \\
0.00 \\
\end{array}$ & $\begin{array}{c}-0.13 \\
0.26 \\
\end{array}$ & $\begin{array}{l}0.26 \\
0.02 \\
\end{array}$ & $\begin{array}{c}-0.09 \\
0.39 \\
\end{array}$ & $\begin{array}{l}0.23 \\
0.03\end{array}$ & $\begin{array}{l}0.20 \\
0.07 \\
\end{array}$ & & & & & & & & & \\
\hline GI & $\begin{array}{l}\mathrm{CC} \\
\mathrm{P} \\
\end{array}$ & $\begin{array}{l}0.18 \\
0.11 \\
\end{array}$ & $\begin{array}{l}0.16 \\
0.16 \\
\end{array}$ & $\begin{array}{l}-0.13 \\
0.24 \\
\end{array}$ & $\begin{array}{l}0.24 \\
0.03 \\
\end{array}$ & $\begin{array}{l}-0.07 \\
0.51 \\
\end{array}$ & $\begin{array}{l}0.17 \\
0.14 \\
\end{array}$ & $\begin{array}{l}0.14 \\
0.23 \\
\end{array}$ & $\begin{array}{l}0.53 \\
0.00 \\
\end{array}$ & & & & & & & & \\
\hline Salivary flow & $\begin{array}{l}\mathrm{CC} \\
\mathrm{p}\end{array}$ & $\begin{array}{l}-0.03 \\
0.77\end{array}$ & $\begin{array}{l}0.08 \\
0.46\end{array}$ & $\begin{array}{l}0.08 \\
0.46\end{array}$ & $\begin{array}{l}0.09 \\
0.42\end{array}$ & $\begin{array}{l}0.06 \\
0.58\end{array}$ & $\begin{array}{l}0.16 \\
0.14\end{array}$ & $\begin{array}{l}0.15 \\
0.18\end{array}$ & $\begin{array}{l}-0.15 \\
0.19 \\
\end{array}$ & $\begin{array}{l}0.07 \\
0.51\end{array}$ & & & & & & & \\
\hline pH_saliva (sample 0) & $\begin{array}{l}\mathrm{CC} \\
\mathrm{P}\end{array}$ & $\begin{array}{l}-0.15 \\
0.19\end{array}$ & $\begin{array}{l}-0.12 \\
0.27 \\
\end{array}$ & $\begin{array}{l}0.07 \\
0.53 \\
\end{array}$ & $\begin{array}{ll}0.01 \\
0.93 \\
\end{array}$ & $\begin{array}{c}-0.06 \\
0.58 \\
\end{array}$ & $\begin{array}{l}-0.09 \\
0.41 \\
\end{array}$ & $\begin{array}{c}-0.10 \\
0.39 \\
\end{array}$ & $\begin{array}{c}-0.10 \\
0.36 \\
\end{array}$ & $\begin{array}{l}0.05 \\
0.66 \\
\end{array}$ & $\begin{array}{l}0.07 \\
0.52 \\
\end{array}$ & & & & & & \\
\hline pH_saliva (sample 1) & $\begin{array}{l}\mathrm{CC} \\
\mathrm{p}\end{array}$ & $\begin{array}{l}-0.08 \\
0.47 \\
\end{array}$ & $\begin{array}{l}-0.05 \\
0.63 \\
\end{array}$ & $\begin{array}{l}0.15 \\
0.17 \\
\end{array}$ & $\begin{array}{l}0.05 \\
0.65 \\
\end{array}$ & $\begin{array}{c}-0.20 \\
0.08 \\
\end{array}$ & $\begin{array}{l}-0.12 \\
0.28 \\
\end{array}$ & $\begin{array}{l}0.07 \\
0.53 \\
\end{array}$ & $\begin{array}{l}0.00 \\
0.98 \\
\end{array}$ & $\begin{array}{l}0.02 \\
0.84 \\
\end{array}$ & $\begin{array}{l}0.03 \\
0.75 \\
\end{array}$ & $\begin{array}{l}0.56 \\
0.00 \\
\end{array}$ & & & & & \\
\hline pH_plaque_to & $\begin{array}{l}\mathrm{CC} \\
\mathrm{P}\end{array}$ & $\begin{array}{l}-0.03 \\
0.79\end{array}$ & $\begin{array}{c}-0.03 \\
0.79\end{array}$ & $\begin{array}{l}0.04 \\
0.68\end{array}$ & $\begin{array}{l}0.06 \\
0.56\end{array}$ & $\begin{array}{l}0.15 \\
0.18\end{array}$ & $\begin{array}{l}0.08 \\
0.48\end{array}$ & $\begin{array}{l}0.11 \\
0.32\end{array}$ & $\begin{array}{l}-0.24 \\
0.03\end{array}$ & $\begin{array}{l}-0.07 \\
0.54\end{array}$ & $\begin{array}{l}0.03 \\
0.78 \\
\end{array}$ & $\begin{array}{l}-0.02 \\
0.81\end{array}$ & $\begin{array}{l}0.00 \\
0.99 \\
\end{array}$ & $\begin{array}{l}-0.04 \\
0.72\end{array}$ & & & \\
\hline pH_plaque_110 & $\begin{array}{l}\mathrm{CC} \\
\mathrm{p}\end{array}$ & $\begin{array}{l}-0.18 \\
0.11\end{array}$ & $\begin{array}{c}-0.14 \\
0.21\end{array}$ & $\begin{array}{l}0.05 \\
0.61\end{array}$ & $\begin{array}{l}-0.22 \\
0.05\end{array}$ & $\begin{array}{l}0.04 \\
0.67\end{array}$ & $\begin{array}{c}-0.10 \\
0.38\end{array}$ & $\begin{array}{c}-0.10 \\
0.37\end{array}$ & $\begin{array}{c}-0.39 \\
0.00\end{array}$ & $\begin{array}{l}-0.27 \\
0.01\end{array}$ & $\begin{array}{l}0.12 \\
0.28\end{array}$ & $\begin{array}{l}-0.08 \\
0.44\end{array}$ & $\begin{array}{c}-0.26 \\
0.02\end{array}$ & $\begin{array}{c}-0.03 \\
0.79\end{array}$ & $\begin{array}{l}0.53 \\
0.00\end{array}$ & & \\
\hline Lactate_plaque_to & $\begin{array}{l}\mathrm{CC} \\
\mathrm{p}\end{array}$ & $\begin{array}{l}0.31 \\
0.00 \\
\end{array}$ & $\begin{array}{l}0.17 \\
0.13 \\
\end{array}$ & $\begin{array}{l}0.16 \\
0.16 \\
\end{array}$ & $\begin{array}{l}0.27 \\
0.01 \\
\end{array}$ & $\begin{array}{l}0.03 \\
0.75\end{array}$ & $\begin{array}{l}0.16 \\
0.16 \\
\end{array}$ & $\begin{array}{l}0.16 \\
0.16 \\
\end{array}$ & $\begin{array}{l}0.44 \\
0.00 \\
\end{array}$ & $\begin{array}{l}0.35 \\
0.00 \\
\end{array}$ & $\begin{array}{l}-0.17 \\
0.13 \\
\end{array}$ & $\begin{array}{c}-0.05 \\
0.65 \\
\end{array}$ & $\begin{array}{l}0.01 \\
0.87 \\
\end{array}$ & $\begin{array}{c}-0.10 \\
0.39 \\
\end{array}$ & $\begin{array}{c}-0.018 \\
0.11 \\
\end{array}$ & $\begin{array}{c}-0.59 \\
0.00\end{array}$ & \\
\hline Lactate_plaque_t10 15 & $\begin{array}{l}\mathrm{CC} \\
\mathrm{p}\end{array}$ & $\begin{array}{l}0.29 \\
0.01\end{array}$ & $\begin{array}{l}0.28 \\
0.01\end{array}$ & $\begin{array}{c}-0.11 \\
0.33\end{array}$ & $\begin{array}{l}0.29 \\
0.00\end{array}$ & $\begin{array}{l}-0.07 \\
0.53\end{array}$ & $\begin{array}{l}0.17 \\
0.13\end{array}$ & $\begin{array}{l}0.15 \\
0.17\end{array}$ & $\begin{array}{l}0.39 \\
0.00\end{array}$ & $\begin{array}{l}0.34 \\
0.00\end{array}$ & $\begin{array}{l}-0.03 \\
0.77\end{array}$ & $\begin{array}{l}0.02 \\
0.83\end{array}$ & $\begin{array}{l}0.17 \\
0.14\end{array}$ & $\begin{array}{l}0.01 \\
0.88\end{array}$ & $\begin{array}{c}-0.19 \\
0.10\end{array}$ & $\begin{array}{l}-0.67 \\
0.00\end{array}$ & $\begin{array}{l}0.75 \\
0.00\end{array}$ \\
\hline
\end{tabular}

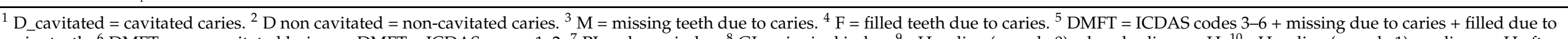

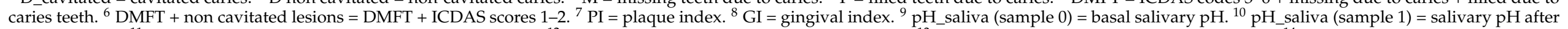

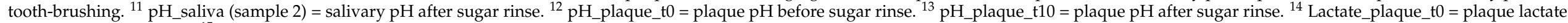
levels before sugar rinse. ${ }^{15}$ Lactate_plaque_t $10=$ plaque lactate levels after sugar rinse. CC: correlation coeficient. Values in bold are statistically significant $(p<0.05)$. 


\subsection{Microbiological Parameters}

The levels of S. mutans and S. dentisani in saliva (CFUs/mL) and plaque (CFUs/ng) were determined after normalizing the quantification according to the total bacterial DNA present. The percentage of both microorganisms was also calculated according to the total number of bacteria present in the plaque material. The levels of S. dentisani in plaque increased significantly when tooth-brushing frequency increased $\left(7.71 \times 10^{2} /\right.$ toothbrushing once a day, $1.42 \times 10^{3} /$ tooth-brushing twice or three times a day) $(p=0.03)$ (the same trends were observed in the percentages of $S$. dentisani in plaque) $(0.29 \% /$ toothbrushing once a day, $0.42 \%$ /tooth-brushing two or three times a day) $(p=0.04)$ (KruskalWallis test). Values of $S$. dentisani $\left(1.38 \times 10^{3} / 1.07 \times 10^{3}\right)$ and percentages of $S$. dentisani in plaque $(0.42 \% / 0.32 \%)$ were higher in patients with DMFT levels $\leq 8$. Levels of $S$. mutans in saliva were higher in patients with baseline salivary pH below $6.4\left(5.29 \times 10^{3} / 1.57 \times 10^{4}\right)$. Plaque normalized $S$. dentisani values and the percentages of $S$. dentisani were slightly higher in patients with lactic acid levels $\leq 50 \mathrm{mg} / \mathrm{L}$. After the sugar rinse, percentages of $S$. mutans levels in plaque were higher in patients with lactic acid levels $>350 \mathrm{mg} / \mathrm{L}$ $(p=0.03)$ (Mann-Whitney U test).

Table 2 shows the correlations between microbiological parameters and clinical and biochemical parameters (Spearman correlation analysis). Age was found to be significantly correlated with $S$. dentisani levels in saliva and plaque. Plaque index was observed to be significantly related to $S$. mutans and $S$. dentisani levels in saliva and the percentages of $S$. dentisani in plaque. The levels of S. mutans and S. dentisani in saliva were significantly associated, as were $S$. mutans levels in plaque and their percentages. Basal $\mathrm{pH}$ in saliva (sample 0 ) was significantly and inversely associated with $S$. dentisani levels. The $\mathrm{pH}$ in plaque at $\mathrm{t} 0$ was found to be significantly and inversely associated with $S$. dentisani levels in saliva and plaque and with $S$. mutans in plaque. $\mathrm{pH}$ at $\mathrm{t} 10$ was found to be significantly and inversely associated with microbiological levels in plaque and saliva. Lactate values at $\mathrm{t} 0$ and $\mathrm{t} 10$ were significantly correlated with microbiological levels in saliva and S. mutans levels in plaque.

Table 2. Correlation analysis (Correlation Coefficient, CC and $p$-value) between the levels of S. mutans and S. dentisani in saliva or plaque with different caries indices and biochemical parameters.

\begin{tabular}{|c|c|c|c|c|c|c|c|}
\hline & & $\begin{array}{l}\text { S. mutans } \\
\text { Saliva }\end{array}$ & $\begin{array}{l}\text { S. dentisani } \\
\text { Saliva }\end{array}$ & $\begin{array}{c}\text { S. dentisani } \\
\text { norm. in Plaque }\end{array}$ & $\begin{array}{l}\text { S. mutans norm. } \\
\text { in Plaque }\end{array}$ & $\begin{array}{l}\% \text { S. dentisani } \\
\text { in Plaque }\end{array}$ & $\begin{array}{c}\% \text { S. Mutans } \\
\text { in Plaque }\end{array}$ \\
\hline \multirow[t]{2}{*}{ Age } & $\mathrm{CC}$ & 0.154 & 0.311 & 0.220 & -0.105 & 0.254 & -0.084 \\
\hline & $\mathrm{p}$ & 0.200 & 0.008 & 0.065 & 0.385 & 0.033 & 0.486 \\
\hline \multirow[t]{2}{*}{ PI $^{1}$} & $\mathrm{CC}$ & 0.27 & 0.412 & 0.226 & 0.098 & 0.246 & 0.040 \\
\hline & $\mathrm{p}$ & 0.020 & 0.000 & 0.058 & 0.415 & 0.039 & 0.742 \\
\hline \multirow[t]{2}{*}{$\mathrm{GI}^{2}$} & $\mathrm{CC}$ & 0.168 & 0.108 & 0.088 & 0.046 & 0.098 & 0.000 \\
\hline & $\mathrm{p}$ & 0.162 & 0.370 & 0.467 & 0.706 & 0.415 & 0.998 \\
\hline \multirow[t]{2}{*}{ Salivary flow } & $\mathrm{CC}$ & -0.034 & -0.197 & -0.036 & 0.048 & -0.142 & -0.015 \\
\hline & $\mathrm{p}$ & 0.777 & 0.100 & 0.763 & 0.688 & 0.236 & 0.899 \\
\hline \multirow{2}{*}{ D_cavitated ${ }^{3}$} & $\mathrm{CC}$ & 0.242 & 0.349 & 0.107 & -0.046 & 0.159 & -0.045 \\
\hline & $\mathrm{p}$ & 0.042 & 0.003 & 0.373 & 0.705 & 0.185 & 0.709 \\
\hline \multirow{2}{*}{$\begin{array}{l}\text { D_cavitaed + non } \\
\text { cavitated }^{4}\end{array}$} & $\mathrm{CC}$ & 0.210 & 0.260 & 0.186 & 0.068 & 0.245 & 0.027 \\
\hline & $\mathrm{p}$ & 0.079 & & 0.119 & 0.574 & 0.039 & 0.823 \\
\hline \multirow{2}{*}{$\mathbf{M}^{5}$} & $\mathrm{CC}$ & 0.149 & 0.150 & 0.068 & 0.085 & 0.018 & 0.114 \\
\hline & $\mathrm{p}$ & 0.214 & 0.211 & 0.574 & 0.479 & 0.882 & 0.346 \\
\hline \multirow{2}{*}{$F^{6}$} & $\mathrm{CC}$ & -0.123 & -0.234 & -0.120 & 0.003 & -0.128 & 0.040 \\
\hline & $\mathrm{p}$ & 0.308 & 0.049 & 0.320 & 0.981 & 0.287 & 0.738 \\
\hline \multirow{2}{*}{ DMFT $^{7}$} & $\mathrm{CC}$ & 0.084 & 0.044 & -0.049 & 0.007 & -0.074 & 0.058 \\
\hline & $\mathrm{p}$ & 0.488 & 0.718 & 0.688 & 0.951 & 0.539 & 0.633 \\
\hline
\end{tabular}


Table 2. Cont.

\begin{tabular}{|c|c|c|c|c|c|c|c|}
\hline & & $\begin{array}{l}\text { S. mutans } \\
\text { Saliva }\end{array}$ & $\begin{array}{l}\text { S. dentisani } \\
\text { Saliva }\end{array}$ & $\begin{array}{c}\text { S. dentisani } \\
\text { norm. in Plaque }\end{array}$ & $\begin{array}{l}\text { S. mutans norm. } \\
\text { in Plaque }\end{array}$ & $\begin{array}{l}\% \text { S. dentisani } \\
\text { in Plaque }\end{array}$ & $\begin{array}{c}\% \text { S. Mutans } \\
\text { in Plaque }\end{array}$ \\
\hline \multirow{2}{*}{$\begin{array}{c}\text { DMFT_with non } \\
\text { cavitated }^{8}\end{array}$} & $\mathrm{CC}$ & 0.110 & 0.037 & -0.001 & 0.053 & -0.012 & 0.084 \\
\hline & $\mathrm{p}$ & 0.363 & 0.760 & 0.993 & 0.659 & 0.919 & 0.484 \\
\hline \multirow{2}{*}{$\begin{array}{c}\begin{array}{c}\text { S. mutans in } \\
\text { saliva }\end{array} \\
\end{array}$} & $\mathrm{CC}$ & & 0.594 & 0.116 & 0.488 & 0.013 & 0.460 \\
\hline & $\mathrm{p}$ & & 0.000 & 0.335 & 0.000 & 0.913 & 0.000 \\
\hline \multirow{2}{*}{$\begin{array}{l}\text { S. dentisani in } \\
\text { saliva }\end{array}$} & $\mathrm{CC}$ & 0.594 & & 0.399 & 0.181 & 0.429 & 0.179 \\
\hline & $\mathrm{p}$ & 0.000 & & 0.001 & 0.131 & 0.000 & 0.136 \\
\hline \multirow{2}{*}{$\begin{array}{l}\text { S. dentisaninorm. } \\
\text { in plaque }\end{array}$} & $\mathrm{CC}$ & 0.116 & 0.399 & & 0.300 & 0.893 & 0.160 \\
\hline & $\mathrm{p}$ & 0.335 & 0.001 & & 0.011 & 0.000 & 0.182 \\
\hline \multirow{2}{*}{$\begin{array}{c}\text { S. mutansnorm. in } \\
\text { plaque }\end{array}$} & $\mathrm{CC}$ & 0.488 & 0.181 & 0.300 & & 0.151 & 0.922 \\
\hline & $\mathrm{p}$ & 0.000 & 0.131 & 0.011 & & 0.208 & 0.000 \\
\hline \multirow{2}{*}{$\begin{array}{c}\% \text { S. dentisani in } \\
\text { plaque }\end{array}$} & $\mathrm{CC}$ & 0.013 & 0.429 & 0.893 & 0.151 & & 0.079 \\
\hline & $\mathrm{p}$ & 0.913 & 0.000 & 0.000 & 0.208 & & 0.512 \\
\hline \multirow{2}{*}{$\begin{array}{c}\% \text { S. mutans in } \\
\text { plaque }\end{array}$} & $\mathrm{CC}$ & 0.460 & 0.179 & 0.160 & 0.922 & 0.079 & \\
\hline & $\mathrm{p}$ & 0.000 & 0.136 & 0.182 & 0.000 & 0.512 & \\
\hline \multirow{2}{*}{$\begin{array}{c}\text { pH_saliva } \\
\text { (sample 0) }\end{array}$} & $\mathrm{CC}$ & -0.177 & -0.238 & -0.103 & -0.111 & -0.124 & -0.154 \\
\hline & $\mathrm{p}$ & 0.139 & 0.046 & 0.392 & 0.359 & 0.302 & 0.201 \\
\hline \multirow{2}{*}{$\begin{array}{c}\text { pH_saliva } \\
(\text { sample 1) }\end{array}$} & $\mathrm{CC}$ & 0.146 & -0.131 & -0.044 & 0.132 & -0.113 & 0.125 \\
\hline & $\mathrm{p}$ & 0.223 & 0.278 & 0.715 & 0.273 & 0.348 & 0.298 \\
\hline \multirow{2}{*}{$\begin{array}{c}\text { pH_saliva } \\
\text { (sample 2) }\end{array}$} & $\mathrm{CC}$ & -0.167 & -0.216 & -0.020 & -0.111 & -0.018 & -0.172 \\
\hline & $\mathrm{p}$ & 0.165 & 0.071 & 0.867 & 0.357 & 0.879 & 0.152 \\
\hline \multirow{2}{*}{ pH_plaque_t0 ${ }^{12}$} & $\mathrm{CC}$ & -0.207 & -0.351 & -0.411 & -0.289 & -0.296 & -0.230 \\
\hline & $\mathrm{p}$ & 0.084 & 0.003 & 0.000 & 0.015 & 0.012 & 0.053 \\
\hline \multirow{2}{*}{ pH_plaque_t10 ${ }^{13}$} & $\mathrm{CC}$ & -0.368 & -0.286 & -0.286 & -0.427 & -0.177 & -0.394 \\
\hline & $\mathrm{p}$ & 0.002 & 0.016 & 0.016 & 0.000 & 0.141 & 0.001 \\
\hline \multirow{2}{*}{$\begin{array}{l}\text { Lactate_plaque } \\
\text { to } 14\end{array}$} & $\mathrm{CC}$ & 0.333 & 0.324 & 0.045 & 0.249 & 0.112 & 0.332 \\
\hline & $\mathrm{p}$ & 0.005 & 0.006 & 0.710 & 0.036 & 0.353 & 0.005 \\
\hline \multirow{2}{*}{$\begin{array}{l}\text { Lactate_plaque } \\
\text { t10 }\end{array}$} & $\mathrm{CC}$ & 0.362 & 0.402 & 0.137 & 0.246 & 0.148 & 0.293 \\
\hline & $\mathrm{p}$ & 0.002 & 0.001 & 0.254 & 0.039 & 0.218 & 0.012 \\
\hline
\end{tabular}

${ }^{1} \mathrm{PI}=$ plaque index. ${ }^{2} \mathrm{GI}=$ gingival index. ${ }^{3} \mathrm{D}$ _cavitated $=$ cavitated caries. ${ }^{4} \mathrm{D} \_$non cavitated $=$non-cavitated caries. ${ }^{5} \mathrm{M}=$ missing teeth due to caries. ${ }^{6} \mathrm{~F}=$ filled teeth due to caries. ${ }^{7} \mathrm{DMFT}=\mathrm{ICDAS}$ scores 3-6 + missing due to caries + filled due to caries teeth. ${ }^{8} \mathrm{DMFT}+$ non cavitated lesions $=$ DMFT + ICDAS scores $1-2 .{ }^{9} \mathrm{pH} \_$saliva $($sample 0$)=$ basal salivary $\mathrm{pH} .{ }^{10} \mathrm{pH} \_$saliva $($sample 1$)=$ salivary $\mathrm{pH}$ after tooth-brushing. ${ }^{11} \mathrm{pH} \_$saliva (sample 2$)=$ salivary $\mathrm{pH}$ after sugar rinse. ${ }^{12} \mathrm{pH} \_$plaque_t $0=$ plaque $\mathrm{pH}$ before sugar rinse. ${ }^{13} \mathrm{pH} \_$plaque_t10 $=$ plaque $\mathrm{pH}$ after sugar rinse. ${ }^{14}$ Lactate_plaque_t $0=$ plaque lactate levels before sugar rinse. ${ }^{15}$ Lactate_plaque_t $10=$ plaque lactate levels after sugar rinse, CC: correlation coefficient. Values in bold are statistically significant $(p<0.05)$.

\section{Discussion}

The mean age of the study sample corresponds to the group of young adults proposed by the WHO, which includes the population between 35 and 44 years old. If that population group is taken as a reference in the data obtained in the last national survey carried out in 2020 then the average DMFT index was $7.40 \pm 4.86$, which is very similar to our sample where the mean DMFT values were $7.45 \pm 4.83$. The mean values of cavitated and filled lesions were similar to those from the national study for the young adult population, while the mean values of missing teeth were lower: 0.73 vs. 1.92 [31]. In the study of Eustaquio M.V. et al. in 2010 on the oral health of the population of the Valencian Region (Spain), similar DMFT values were observed in young adults [32] to those of the present study (7.45 vs. 7.64$)$.

With regards to the association between gender and tooth-brushing frequency, it was observed that men brushed less frequently than women. It was also observed that men had higher DMFT values and its components, with the exception of the restoration index which was higher among women. However, a significant difference was only found in 
component $\mathrm{M}$ (missing to caries). These data are consistent with those found in the 2020 national epidemiological study [31]. In different studies, the direct relationship between tooth-brushing habits and the previous experience of caries has been verified [33-36]. Regarding the plaque and gingival indices, these were also higher in men although the difference was only significant for the plaque index. These data are consistent with those found in the literature $[31,36,37]$. However, a limitation of the present study could be not having taken into account other relevant factors in caries etiology such as diet, social and behavioral factors as well as the difference in sample size between men and women. Thus, although the microbiological and biochemical features measured in the current study correspond only to 75 individuals, this agreement in clinical data with the national survey suggests that we are working on a representative set of individuals.

Additionally, significantly higher levels of $S$. mutans were found in plaque and in saliva in men than compared to women. These data are correlated with the results obtained regarding the plaque index. Good oral hygiene habits control the oral microbiota at levels compatible with health [38] and our data suggest better oral hygiene parameters in women, which is translated in better clinical and microbiological features. Likewise, lactate levels were higher in men both before and after the sugar rinse. This can be explained because higher concentrations of lactate are related to a greater amount of plaque with acidogenic properties. It is well established that acidogenic and aciduric biofilms are associated with an increased risk of disease [39]. In a recent study that microbiologically evaluated 268 young patients in the Netherlands, a strong gender pattern was also observed in microbial composition and metabolism and more cariogenic microbiota was observed in men resulting in significant $\mathrm{pH}$ differences [40].

With the data obtained in the present study, it can be highlighted that factors associated with gender influences the incidence of dental caries; it is observed that men have poorer oral health and that women take greater care of their oral hygiene both individually (toothbrushing) and professionally (restorations). Nevertheless, other factors such as dietary habits or sociocultural and behavioral factors should also be considered when estimating the risk of developing caries.

After analyzing the tooth-brushing frequency with the quantitative variables, it was observed that the participants who brushed their teeth once a day had worse oral health than those who did so 2-3 times a day. In addition, participants who brushed their teeth three times a day had a significantly lower gingival index and lower plaque lactate content. The beneficial effect of tooth-brushing on the risk of caries has been demonstrated in numerous studies and is the most effective method for removing plaque [41] and the best fluoride delivery system [42]. Consequently, it can be concluded that brushing three times a day reduces the risk of tooth decay and that brushing frequency is predictive of caries risk. In agreement with this, it is interesting that the levels of the cariogenic bacterium $S$. mutans corelated negatively with tooth-brushing frequency but positively with the health-associated species $S$. dentisani.

When correlating the clinical and laboratory variables, it was observed that DMFT increases with age, that tooth absences are significantly related to plaque and gingival indices and that plaque and gingival indices have a significant association with $\mathrm{pH}$ levels and lactate content before and after the sugar rinse. In 1987, Firestone et al. verified how the maturity of dental plaque considerably increases the drop in $\mathrm{pH}$ after a meal ingestion [43]. This fact supports the correlation observed between plaque index, $\mathrm{pH}$ and lactate content of the plaque itself. Experimental studies have also demonstrated the association between certain microbial components of mature plaque and the ability to modify $\mathrm{pH}$, lactic acid production and the presence of enzymes with high pathogenic potential [3].

Among the factors associated with microbiology, lactate is the most reliable marker of caries. Given that this marker was measured in plaque and that $S$. mutans levels were better correlated with caries parameters when this bacterium was quantified in plaque, the present work supports the use of dental plaque to measure microbiological parameters with greater reliability than saliva, which showed erratic and inconsistent trends in the 
different factors measured. Despite this fact, it is interesting that the levels of both S. mutans and $S$. dentisani in plaque were significantly correlated with the values of these bacteria in saliva. This is possibly due to the fact that both species are mainly inhabitants of hard tissues and, therefore, their higher levels in plaque imply a greater release in saliva. Other streptococci which are found at high levels in soft tissues, such $S$ salivarius, may not correlate between these two niches.

Microbiological data support that, despite the fact that $S$. mutans is a minor inhabitant of dental plaque representing less than $1 \%$ of the total microbiota, its presence is correlated with lactate production and is therefore an important bacterium in acid generation [12]. However, the correlations of this bacterium with caries levels were neither positive nor significant, neither with $\mathrm{pH}$ values nor with caries levels or caries indices. Future studies should include the levels of other acidogenic bacteria in order to establish the microbiological risk of caries more accurately. It was observed, for example, that the measurement of S. mutans and Lactobacillus in a combined manner correlates more with caries parameters than each one separately [44]. Other authors are trying to incorporate other bacterial species in the map of the prediction of the risk of suffering from the disease [45].

The levels of $S$. dentisani were higher in individuals without restorations, which could indicate a negative association with the history of caries, while the opposite pattern was detected in S. mutans. However, these data were inconsistent with the levels of active caries or cavitated caries and thus there is no clear protective relationship between the presence of $S$. dentisani and caries in individuals who already have the disease. Given that there are higher levels of $S$. dentisani in individuals without caries [13], it is possible that the beneficial effect of $S$. dentisani requires minimal levels of the bacteria to be effective although it cannot be ruled out that said protective effect depends on the strain of $S$. dentisani present in each individual.

Unlike what occurred with $S$. mutans, $S$. dentisani levels did not correlate with lactate production in plaque, although the percentage of $S$. dentisani in plaque was higher in patients with lower lactate levels both before and after the sugar rinse. However, the levels of both bacteria before and after the sugar rinse were negatively related to plaque $\mathrm{pH}$. This suggests that $\mathrm{pH}$ is related to the total amount of plaque or bacterial load, regardless of whether or not the protective effect of $S$. dentisani was present.

In in vitro experiments, it has been shown that the buffer effect of $S$. dentisani through the arginine pathway requires several hours [14] and therefore would not be appreciated in the data of the present work. A second explanation for this lack of correlation between $\mathrm{pH}$ and levels of $S$. dentisani would be given by the absence of individuals without caries $[\mathrm{DMFT}=0$ ] in the study since it is these individuals who have shown higher levels of $S$. dentisani and of arginolytic activity in general $[18,46]$. Therefore, the data would support the idea that once the disease is present, the levels of $S$. dentisani in these individuals are not sufficient to prevent either $S$. mutans levels or lactate production or to maintain a more alkaline basal $\mathrm{pH}$. In fact, it is surprising that despite the substantial inhibition produced by this bacterium against cariogenic organisms under laboratory conditions, there is no negative correlation between the presence of $S$. dentisani and the levels of $S$. mutans. Future work should therefore establish this correlation in individuals who have never suffered caries.

In a recently published article, it has been shown that the administration of a bioadhesive gel, applied with individualized trays for a week, containing the probiotic $S$ dentisani causes an increase in salivary $\mathrm{pH}$, a reduction in the production of lactic acid up to 30 days after its application, a reduction in the colonization of $S$ mutans and an increase in the presence of $S$ dentisani up to 14 days after its application [47]. In a second clinical trial where the probiotic was applied for a month, improvements in plaque and gingival indices, as well as in salivary ammonia and pathogen levels were observed [48] and this suggests, again, that there is minimum level of this organism that is necessary to observe an improvement in clinical and microbiological features. 
Meanwhile, in patients who already have the disease, our data strongly confirm that tooth-brushing is the most effective method to improve caries risk and the development of cavities [41,42]. In this sense, the significant correlation that exists between tooth-brushing and S. dentisani levels is interesting and it indicates that this bacterium is favored by correct oral hygiene. This suggests that it is an early colonizer of the plaque and/or that it is favored by the lower frequency of a mature and acidogenic plaque. Therefore, a synergistic effect could occur between tooth-brushing and the presence of $S$. dentisani as it has been observed after tongue-brushing for other beneficial organisms such as Rothia [48]. Given that S. dentisani uses arginine for its $\mathrm{pH}$ buffering action [45], it would be interesting to test whether the use of arginine toothpastes and the administration of $S$. dentisani as a probiotic can have a synergistic effect in individuals with cavities.

\section{Conclusions}

Tooth-brushing frequency was the most decisive factor associated with oral health. Low $\mathrm{pH}$ and high lactic acid levels tended to be associated with higher caries rates. However, no association was found between the levels of specific bacteria and dental caries and this suggests that a single bacterial species cannot be used as a valid biomarker of the disease.

Author Contributions: Conceptualization, A.M. and C.L.; methodology, M.D.F. and A.L.L.; formal analysis, A.M. and C.L.; investigation, S.P., M.D.F. and A.L.L.; data curation, A.M. and C.L.; writing - original draft preparation, M.M.; writing—review and editing, J.L.S.; supervision, A.M. and C.L.; funding acquisition, A.M. All authors have read and agreed to the published version of the manuscript.

Funding: This research received funding by grant RTC-2015-4292-1 from the RETOS-Colaboración Call of the Spanish Ministry of Health and Competitiveness and by grant RTI2018-102032-B-I00 from the Spanish Ministry of Science, Innovation and Universities.

Institutional Review Board Statement: The study was conducted according to the guidelines of the Declaration of Helsinki and approved by the Ethics Committee of FISABIO foundation (CEIC DGSP-CSISP).

Informed Consent Statement: Informed consent was obtained from all subjects involved in the study.

Data Availability Statement: The data presented in this study are available upon request from the corresponding author.

Conflicts of Interest: The authors declare no conflict of interest.

\section{References}

1. Machiulskiene, V.; Campus, G.; Carvalho, J.C.; Dige, I.; Ekstrand, K.R.; Jablonski-Momeni, A.; Maltz, M.; Manton, D.J.; Martignon, S.; Martinez-Mier, E.A.; et al. Terminology of Dental Caries and Dental Caries Management: Consensus Report of a Workshop Organized by ORCA and Cariology Research Group of IADR. Caries Res. 2020, 54, 7-14. [CrossRef]

2. Morou-Bermudez, E.; Elias-Boneta, A.; Billings, R.J.; Burne, R.A.; Garcia-Rivas, V.; Brignoni-Nazario, V.; Suarez Perez, E. Urease activity in dental plaque and saliva of children during a three-year study period and its relationship with other caries risk factors. Arch. Oral Biol. 2011, 56, 1282-1289. [CrossRef] [PubMed]

3. Simon-Soro, A.; Mira, A. Solving the etiology of dental caries. Trends Microbiol. 2015, 23, 76-82. [CrossRef]

4. Simon-Soro, A.; Guillen-Navarro, M.; Mira, A. Metatranscriptomics reveals overall active bacterial composition in caries lesions. J. Oral Microbiol. 2014, 6, 25443. [CrossRef]

5. Marsh, P.D. Are dental diseases examples of ecological catastrophes? Microbiology 2003, 149, 279-294. [CrossRef] [PubMed]

6. Paes Leme, A.F.; Koo, H.; Bellato, C.M.; Bedi, G.; Cury, J.A. The role of sucrose in cariogenic dental biofilm formation-New insight. J. Dent. Res. 2006, 85, 878-887. [CrossRef] [PubMed]

7. Sheng, J.; Baldeck, J.D.; Nguyen, P.T.; Quivey, R.G., Jr.; Marquis, R.E. Alkali production associated with malolactic fermentation by oral streptococci and protection against acid, oxidative, or starvation damage. Can. J. Microbiol. 2010, 56, 539-547. [CrossRef] [PubMed]

8. Huang, X.; Exterkate, R.A.; ten Cate, J.M. Factors associated with alkali production from arginine in dental biofilms. J. Dent. Res. 2012, 91, 1130-1134. [CrossRef]

9. Simón-Soro, A.; Tomás, I.; Cabrera-Rubio, R.; Catalan, M.D.; Nyvad, B.; Mira, A. Microbial geography of the oral cavity. J. Dent. Res. 2013, 92, 616-621. [CrossRef] [PubMed] 
10. Alcaraz, L.D.; Belda-Ferre, P.; Cabrera-Rubio, R.; Romero, H.; Simón-Soro, A.; Pignatelli, M.; Mira, A. Identifying a healthy oral microbiome through metagenomics. Clin. Microbiol. Infect. 2012, 18 (Suppl. S4), 54-57. [CrossRef]

11. Benítez-Páez, A.; Belda-Ferre, P.; Simón-Soro, A.; Mira, A. Microbiota diversity and gene expression dynamics in human oral biofilms. BMC Genom. 2014, 15, 311. [CrossRef] [PubMed]

12. Belda-Ferre, P.; Alcaraz, L.D.; Cabrera-Rubio, R.; Romero, H.; Simon-Soro, A.; Pignatelli, M.; Mira, A. The oral metagenome in health and disease. ISME J. 2012, 6, 46-56. [CrossRef]

13. Camelo-Castillo, A.; Benitez-Paez, A.; Belda-Ferre, P.; Cabrera-Rubio, R.; Mira, A. Streptococcus dentisani sp. a novel member of the mitis group. Int. J. Syst. Evol. Microbiol. 2014, 64, 60-65. [CrossRef] [PubMed]

14. Lopez-Lopez, A.; Camelo-Castillo, A.; Ferrer, M.D.; Simon-Soro, A.; Mira, A. Health-Associated Niche Inhabitants as Oral Probiotics: The Case of Streptococcus dentisani. Front. Microbiol. 2017, 8, 379. [CrossRef] [PubMed]

15. Rosier, B.T.; Buetas, E.; Moya-Gonzalvez, E.M.; Artacho, A.; Mira, A. Nitrate as a potential prebiotic for the oral microbiome. Sci. Rep. 2020, 10, 12895. [CrossRef]

16. Nascimento, M.M.; Gordan, V.V.; Garvan, C.W.; Browngardt, C.M.; Burne, R.A. Correlations of oral bacterial arginine and urea catabolism with caries experience. Oral Microbiol. Immunol. 2009, 24, 89-95. [CrossRef]

17. Gordan, V.V.; Garvan, C.W.; Ottenga, M.E.; Schulte, R.; Harris, P.A.; McEdward, D.; Magnusson, L. Could alkali production be considered an approach for caries control? Caries Res. 2010, 44, 547-554. [CrossRef]

18. Nascimento, M.M.; Liu, Y.; Kalra, R.; Perry, S.; Adewumi, A.; Xu, X.; Primosch, R.E.; Burne, R.A. Oral arginine metabolism may decrease the risk for dental caries in children. J. Dent Res. 2013, 92, 60460-60468. [CrossRef]

19. Hassan, H.; Lingstrom, P.; Carlen, A. Plaque $\mathrm{pH}$ in caries-free and caries-active young individuals before and after frequent rinses with sucrose and urea solution. Caries Res. 2015, 49, 18-25. [CrossRef]

20. Dawes, C. What is the critical pH and why does a tooth dissolve in acid? J. Can. Dent. Assoc. 2003, 69, 722-724. [PubMed]

21. Kleinberg, I. A mixed-bacteria ecological approach to understanding the role of the oral bacteria in dental caries causation: An alternative to Streptococcus mutans and the specific-plaque hypothesis. Crit. Rev. Oral Biol. Med. 2002, 13, 108-125. [CrossRef]

22. Aminabadi, N.A.; Najafpour, E.; Razavi Rohani, Z.; Sighari Deljavan, A.; Ghojazadeh, M.; Jamali, Z. Linear reciprocal interaction between dental caries and salivary characteristics. J. Oral Sci. 2013, 55, 337-342. [CrossRef] [PubMed]

23. Lenander-Lumikari, M.; Loimaranta, V. Saliva and dental caries. Adv. Dent Res. 2000, 14, 40-47. [CrossRef]

24. Löe, H. The gingival index, the plaque index and the retention index systems. J. Periodontol. 1967, 38, 610-616. [CrossRef]

25. Ekstrand, K.R.; Gimenez, T.; Ferreira, F.R.; Mendes, F.M.; Braga, M.M. The International Caries Detection and Assessment System-ICDAS: A Systematic Review. Caries Res. 2018, 52, 406-419. [CrossRef]

26. Dzidic, M.; Collado, M.C.; Abrahamsson, T.; Artacho, A.; Stensson, M.; Jenmalm, M.C.; Mira, A. Oral microbiome development during childhood: An ecological succession influenced by postnatal factors and associated with tooth decay. ISME J. 2018, 12, 2292-2306. [CrossRef] [PubMed]

27. Yano, A.; Kaneko, N.; Ida, H.; Yamaguchi, T.; Hanada, N. Real-time PCR for quantification of Streptococcus mutans. FEMS Microbiol. Lett. 2002, 217, 23-30. [CrossRef] [PubMed]

28. Caporaso, J.G.; Lauber, C.L.; Walters, W.A.; Berg-Lyons, D.; Lozupone, C.A.; Turnbaugh, P.J.; Fierer, N.; Knight, R. Global patterns of $16 \mathrm{~S}$ rRNA diversity at a depth of millions of sequences per sample. Proc. Natl. Acad. Sci. USA 2011, 108, 4516-4522. [CrossRef]

29. Cruaud, P.; Vigneron, A.; Lucchetti-Miganeh, C.; Ciron, P.E.; Godfroy, A.; Cambon-Bonavita, M.A. Influence of DNA extraction method, 16S rRNA targeted hypervariable regions, and sample origin on microbial diversity detected by 454 pyrosequencing in marine chemosynthetic ecosystems. Appl. Environ. Microbiol. 2014, 80, 4626-4639. [CrossRef]

30. Braga, M.M.; Oliveira, L.B.; Bonini, G.A.; Bönecker, M.; Mendes, F.M. Feasibility of the International Caries Detection and Assessment System (ICDAS-II) in epidemiological surveys and comparability with standard World Health Organization criteria. Caries Res. 2009, 43, 245-249. [CrossRef]

31. Bravo Perez, M.; Almerich Silla, J.M.; Canorea Díaz, E.; Casals, P.; Cortes Martinicorena, F.J.; Expósito Delgado, A.; Gómez Santos, G.; Hidalgo Olivares, G.; Lamas Oliveira, M.; Martínez Beneyto, Y.; et al. Oral Health Survey in Spain 2020. RCOE 2020, 25, 12-69.

32. Eustaquio, M.V.; Montiel, J.M.; Almerich, J.M. Oral health survey of the adult population of the Valencia region (Spain). Med. Oral Patol. Oral Cir. Bucal. 2010, 15, e538-e544. [CrossRef]

33. Zeng, L.; Peng, Y.; Xu, T.; Wen, J.; Wan, L.; Ou, X.; Zhou, X. Dental caries and associated factors among adolescents aged 12 to 15 in Jiangxi Province, China. Public Health Dent. 2020, 80, 217-226. [CrossRef] [PubMed]

34. Carta, G.; Cagetti, M.G.; Cocco, F.; Sale, S.; Lingstrom, P.; Campus, G. Caries-risk profiles in Italian adults using computer caries assessment system and ICDAS. Braz. Oral Res. 2015, 29, 1-8. [CrossRef]

35. Broadbent, J.M.; Zeng, J.; Foster Page, L.A.; Baker, S.R.; Ramrakha, S.; Thomson, W.M. Oral Health-Related Beliefs, Behaviors, and Outcomes through the Life Course. J. Dent Res. 2016, 95, 808-813. [CrossRef] [PubMed]

36. Arrica, M.; Carta, G.; Cocco, F.; Cagetti, M.G.; Campus, G.; Ierardo, G.; Ottolenghi, L.; Salee, S.; Strohmenger, L. Does a social/behavioural gradient in dental health exist among adults? A cross-sectional study. J. Int. Med. Res. 2017, 45, 451-461. [CrossRef] [PubMed]

37. Vano, M.; Gennai, S.; Karapetsa, D.; Miceli, M.; Giuca, M.R.; Gabriele, M.; Graziani, F. The influence of educational level and oral hygiene behaviours on DMFT index and CPITN index in an adult Italian population: An epidemiological study. Int. J. Dent. Hyg. 2015, 13, 151-157. [CrossRef]

38. Marsh, P.D.; Head, D.A. Ecological approaches to oral biofilms: Control without killing. Caries Res. 2015, 49, 46-54. [CrossRef] 
39. Tanner, A.C.; Kressirer, C.A.; Faller, L.L. Understanding Caries from the Oral Microbiome Perspective. J. Calif Dent. Assoc. 2016, $44,437-446$.

40. Zaura, E.; Brandt, B.W.; Prodan, A.; Teixeira de Mattos, M.J.; Imangaliyev, S.; Kool, J.; Buijs, M.J.; Jagers, F.L.; Hennequin-Hoenderdos. N.L.; Slot, D.E.; et al. On the ecosystemic network of saliva in healthy young adults. ISME J. 2017, 11, 1218-1231. [CrossRef] [PubMed]

41. Struzycka, I. The oral microbiome in dental caries. Pol. J. Microbiol. 2014, 63, 127-135. [CrossRef]

42. Firestone, A.R.; Graves, C.; Caufield, P.W.; Feagin, F.F. Root surface caries subsequent to gingivectomy in rats inoculated with Streptococcus sobrinus, mutans and Actinomyces viscosus. J. Dent. Res. 1987, 66, 1583-1586. [CrossRef]

43. Elgamily, H.M.; Gamal, A.A.; Saleh, S.A.A.; Abdel Wahab, W.A.; Hashem, A.M.; Esawy, M.A. Microbiological and environmental assessment of human oral dental plaque isolates. Microb. Pathog. 2019, 135, 103626. [CrossRef] [PubMed]

44. Tanner, A.C.R.; Kressirer, C.A.; Rothmiller, S.; Johansson, I.; Chalmers, N.I. The Caries Microbiome: Implications for Reversing Dysbiosis. Adv. Dent. Res. 2018, 29, 78-85. [CrossRef]

45. Moncada, G.; Maureira, J.; Neira, M.; Reyes, E.; Oliveira Junior, O.B.; Faleiros, S.; Palma, P.; Corsini, G.; Ugalde, C.; Gordan, V.V.; et al. Salivary Urease and ADS Enzymatic Activity as Endogenous Protection against Dental Caries in Children. J. Clin. Pediatr. Dent. 2015, 39, 358-363. [CrossRef] [PubMed]

46. Ferrer, M.D.; López-López, A.; Nicolescu, T.; Salavert, A.; Méndez, I.; Cuñé, J.; Llena, C.; Mira, A. A pilot study to assess oral colonization and $\mathrm{pH}$ buffering by the probiotic Streptococcus dentisani under different dosing regimens. Odontology 2020, 108, 180-187. [CrossRef]

47. Ferrer, M.D.; López-López, A.; Nicolescu, T.; Perez-Vilaplana, S.; Boix-Amorós, A.; Dzidic, M.; Garcia, S.; Artacho, A.; Llena, C.; Mira, A. Topic Application of the Probiotic Streptococcus dentisani Improves Clinical and Microbiological Parameters Associated with Oral Health. Front. Cell Infect. Microbiol. 2020, 10, 465. [CrossRef]

48. Tribble, G.D.; Angelov, N.; Weltman, R.; Wang, B.Y.; Eswaran, S.V.; Gay, I.C.; Parthasarathy, K.; Dao, D.V.; Richardson, K.N.; Ismail, N.M.; et al. Frequency of Tongue Cleaning Impacts the Human Tongue Microbiome Composition and Enterosalivary Circulation of Nitrate. Front. Cell Infect. Microbiol. 2019, 9, 39. [CrossRef] [PubMed] 